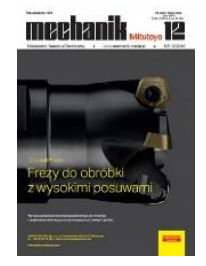

How to cite this article:

Authors: Agata Felusiak, Martyna Wiciak-Pikuła, Tadeusz Chwalczuk, Piotr Kieruj, Paweł Twardowski

Title of article: "Surface roughness characterization of stainless steel after laser assisted machining"

Mechanik, No. 12 (2019)

DOI: https://doi.org/10.17814/mechanik.2019.12.113

\title{
Surface roughness characterization of stainless steel after laser assisted machining
}

\author{
AGATA FELUSIAK \\ MARTYNA WICIAK-PIKUŁA \\ TADEUSZ CHWALCZUK \\ PIOTR KIERUJ \\ PAWEE TWARDOWSKI *
}

Mgr inż. Agata Felusiak, agata.z.felusiak@doctorate.put.poznan.pl, https://orcid.org/0000-0002-4927-4120 - Politechnika Poznańska, Wydział Budowy Maszyn i Zarządzania, Instytut Technologii Mechanicznej, Poznań, Polska

Mgr inż. Martyna Wiciak-Pikuła, martyna.r.wiciak@doctorate.put.poznan.pl, https://orcid.org/0000-0003-2648-7091 - Politechnika Poznańska, Wydział Budowy Maszyn i Zarządzania, Instytut Technologii Mechanicznej, Poznań, Polska

Mgr inż. Tadeusz Chwalczuk, tadeusz.chwalczuk@put.poznan.pl, https://orcid.org/0000-0002-4009-0552 - Politechnika Poznańska, Wydział Budowy Maszyn i Zarządzania, Instytut Technologii Mechanicznej, Poznań, Polska

Mgr inż. Piotr Kieruj, piotr.kieruj@put.poznan.pl, https://orcid.org/0000-0002-7110-7732 - Politechnika Poznańska, Wydział Budowy Maszyn i Zarządzania, Instytut Technologii Mechanicznej, Poznań, Polska

Dr hab. inż. Paweł Twardowski, pawel.twardowski@put.poznan.pl, https://orcid.org/0000-0002-1823-6279 - Politechnika Poznańska, Wydział Budowy Maszyn i Zarządzania, Instytut Technologii Mechanicznej, Poznań, Polska

The paper presents the analysis of the influence of laser assisted machining (LAM) on various parameters of surface roughness of stainless steel. The tests were carried out for cemented carbide inserts with varying cutting parameters. In most cases, a significant reduction in the roughness parameters was observed using LAM.

KEYWORDS: stainless steel, laser assisted machining, turning, surface roughness

\section{Introduction}

Although stainless steel is widely used, its processing still presents some problems. Due to the low thermal conductivity (compared to structural steels), as well as tendency to strengthen during machining and the formation of adhesive bonds with the material, austenitic stainless steels are classified as difficult to cut materials. Low thermal conductivity causes the occurrence of high temperature in the cutting zone, which contributes to shortening the life of the cutting edge [1].

X2CrNiMo17-12-2 austenitic steel is very widely used in industry, e.g. food and chemical (used to make tanks, pipes, surgical instruments), in jewelry, as well as material for ship or vehicle construction elements.

An important issue for machining materials (not only stainless steels, but any construction material) is to produce a top layer of suitable quality. Geometrical structure of the surface is important, especially due to its functional properties, such as flow resistance, fatigue strength and tightness of joints [2].

In order to improve the machinability of difficult-to-cut materials, hybrid machining methods, e.g. laser assisted machining (LAM), are used. Laser support consists in heating the processed material - in order to soften it - with a high-power laser beam, which reduces the cutting forces and the material's strength during cutting [3]. LAM technology is often used to facilitate the machining of difficult-to-cut materials - nickel alloys $[4,5]$, titanium alloys [6] or stainless steels [7-11].

In the quoted works, positive effects of the use of laser cutting support were pointed out, such as: reduction of resistance forces during cutting, improvement of the quality of the machined surface and extension of the durability of cutting edge.

In [4], the authors confirmed the possibility of reducing the $S a$ parameter of surface roughness by more than $50 \%$ compared to traditional turning - due to the use of laser support. In addition, researchers noted that the adopted machining strategy has large impact on the microhardness of the machined surface. 
In paper [5], it was noted that the effect of using excessive power laser is too intense plasticization of the machined material and deterioration of the surface quality. According to work [7], laser support for martensitic stainless steel milling allows even a double reduction of cutting edge wear compared to conventional machining (sintered tungsten carbide inserts were used in the tests), while it does not change the nature of wear - both in traditional machining and in laser assisted machining adhesive and abrasive wear dominated. Researchers also found a decrease in the cutting force value of about 1/3.

In the paper [8], the authors argue that at laser heating of austenitic steel samples at the melting site, a dendritic structure is created, which is easier to machine, while the microhardness of the melted zone does not change compared to the unmelted zone. The penetration depth was strongly influenced by the absorption coating (gouache), which covered the workpiece. Samples with an absorbing layer had a greater depth of remelting than uncoated samples, although the same laser beam power was used in the tests.

In [9], the authors examined the effects of laser support for turning stainless steel with an austeniticmartensitic structure 15-5PH. They found a slight decrease in cutting forces as well as an increase in roughness parameters and an increase in the cutting edge life compared to conventional turning.

The work [10] discusses the effect of laser turning support for AISI 52100 chromium steel with ceramic inserts. Researchers observed a clear reduction in cutting forces and improved surface quality.

The authors of [11] examined the possibility of using LAM technology in micro-milling of high-nickel stainless steel A-286 (43HRC). During the tests, they obtained approximately 30\% higher tool life (compared to machining without the use of LAM), $10 \%$ lower cutting forces and higher dimensional and shape accuracy of the groove being made.

\section{Research methodology}

The tests were carried out at the Cutting Machining Plant at the Poznan University of Technology. A $72 \mathrm{~mm}$ diameter shaft was machined, made of X2CrNiMo17-12-2 steel, the composition of which according to the European standard PN-EN 10088 is given in tab. I. Cutting was carried out using Sandvik cemented carbide CNMG120408-MF 1115 inserts. TRUMPF diode laser TruDiode 3004 was used for laser assisted cutting. Eight tests of conventional machining and machining with simultaneous heating of the machined material with a laser beam with constant energy equal to $1.2 \mathrm{~J} / \mathrm{mm}^{2}$ and constant beam diameter equal to $1.2 \mathrm{~mm}$ were carried out. Due to the constant energy density, the laser power was variable. The cutting data values are given in tab. II. The research was based on a bivalent plan. Fig. 1 shows a laser assisted turning station and way of fixing the workpiece.

Each surface machined was subjected to five roughness measurements. The stationary profilometer T8000 was used to assess surface topography. The measuring length $l_{\mathrm{n}}=4 \mathrm{~mm}$ and the elementary segment $l_{\mathrm{r}}=0.08$ $\mathrm{mm}$ were used in accordance with PN-ISO 4288: 1998. On the basis of the surface profiles obtained, roughness profiles were calculated: $R a, R z, R t, R s k, R q, R S m, R d q$.

TABLE I. Chemical composition of X2CrNiMo17-12-2 steel according to PN-EN 10088

\begin{tabular}{|c|c|c|c|c|c|c|c|c|c|}
\hline Element & $\mathrm{C}$ & $\mathrm{Si}$ & $\mathrm{Mn}$ & $\mathrm{P}$ & $\mathrm{S}$ & $\mathrm{N}$ & $\mathrm{Cr}$ & Mo & $\mathrm{Ni}$ \\
\hline \multirow{2}{*}{ Percentage } & up to & up to & up to & up to & up to & up to & $16.50 \div 18.50$ & $2.00 \div 2.50$ & \multirow{2}{*}{$10.00 \div 13.00$} \\
\hline
\end{tabular}

TABLE II. Process parameters used during the experiment

\begin{tabular}{|c|c|c|c|c|}
\hline Code & $a_{\mathrm{p}}[\mathrm{mm}]$ & $v_{\mathrm{c}}[\mathrm{m} / \mathrm{min}]$ & $f[\mathrm{~mm} / \mathrm{obr}]$ & $P[\mathrm{~W}]$ \\
\hline $\mathrm{s} 1$ & 0.1 & 75 & 0.15 & 1800 \\
\hline $\mathrm{s} 2$ & 0.3 & 75 & 015 & 1800 \\
\hline $\mathrm{s} 3$ & 0.1 & 50 & 0.08 & 1200 \\
\hline $\mathrm{s} 4$ & 0.3 & 50 & 0.08 & 1200 \\
\hline $\mathrm{s} 5$ & 0.3 & 75 & 0.08 & 1800 \\
\hline $\mathrm{s} 6$ & 0.1 & 75 & 0.08 & 1800 \\
\hline $\mathrm{s} 7$ & 0.3 & 50 & 0.15 & 1200 \\
\hline $\mathrm{s} 8$ & 0.1 & 50 & 0.15 & 1200 \\
\hline
\end{tabular}




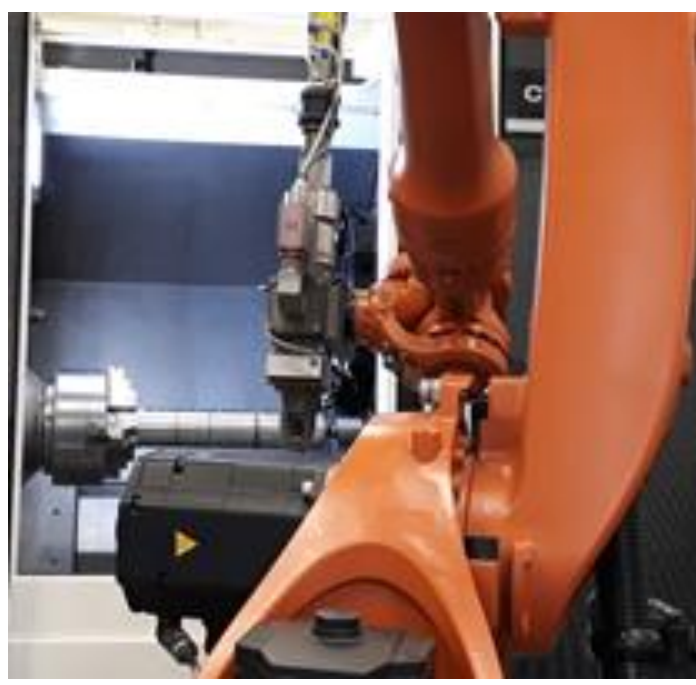

Fig. 1. Station for laser cutting support with attached element

\section{Research results and analysis}

Based on the conducted research, an analysis of the impact of the applied cutting parameters and energy density was carried out using the Pareto method of effects for the confidence level of 0.05 . The results are presented in the form of graphs (fig. 2).

For height parameters of roughness $(R a, R z$, and especially $R t)$, the combination of cutting depth and feedrate has the greatest impact on the value.

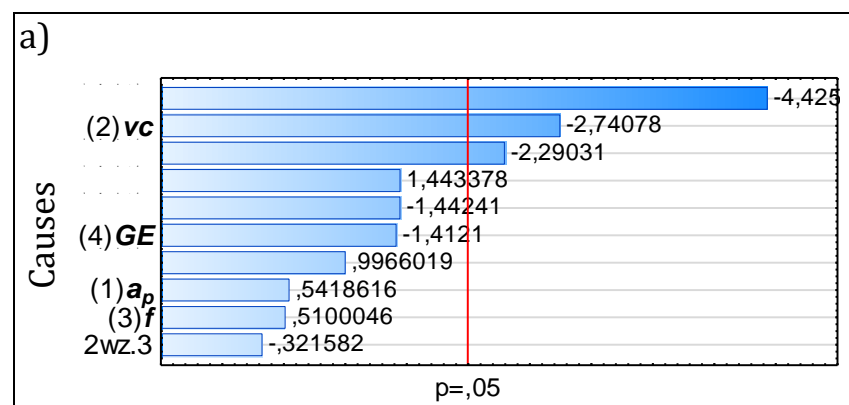

Absolute value of the standardized effect assessment

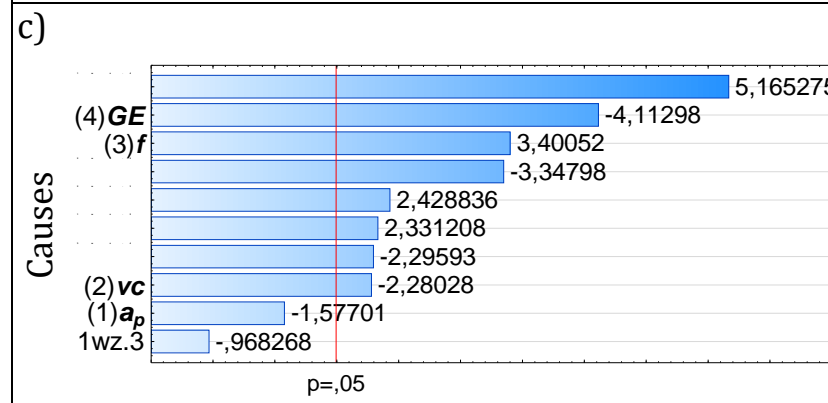

Absolute value of the standardized effect assessment

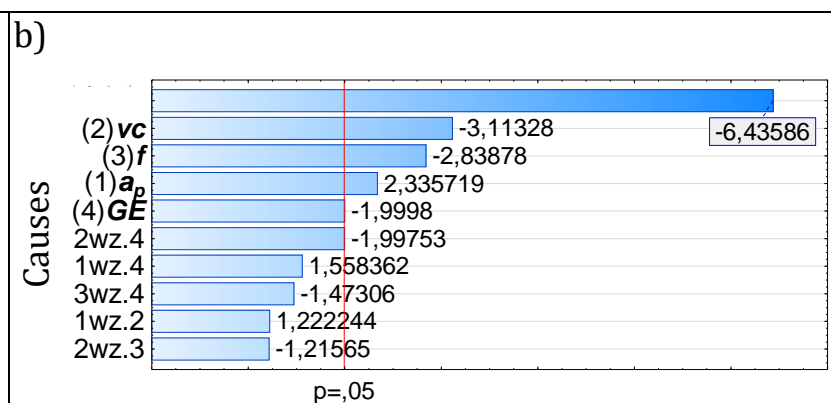

Absolute value of the standardized effect assessment

d)

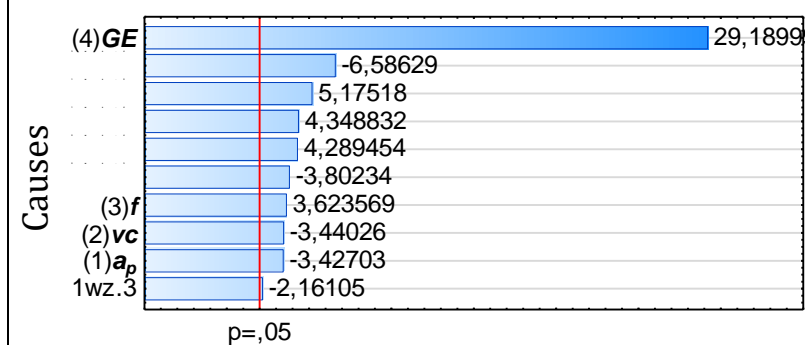

Absolute value of the standardized effect assessment

\section{Fig. 2. Pareto effects chart for roughness parameters: a) $R a$, b) $R t$, c) $R S m$, d) $R s k$}

In the case of the Rt parameter, the use of laser assistance affects it to a small extent and is on the border of significance (fig. 2b). The significance of the influence of settings on the $R S m$ roughness parameter is different (fig. 2c). Here, the most important are combinations of cutting depth with laser assist. In the case of asymmetry and amplitude parameters $(R s k, R k u)$, the most important factor affecting their values is whether or not laser cutting assist is used, with all settings and their combinations having a significant impact on these roughness parameters. 
The diagrams (fig. 3) compare the average values of surface roughness parameters (averaged over five measurements), machined with and without laser cutting assistance.

For roughness height parameters, the average values are as in fig. $3 a$.

With the most favorable selection of settings (s2) and the use of laser assist, a significant reduction was obtained: $R a$ - by approximately $53 \%, R z$ - by approximately $38 \%, R t$ - by approximately $50 \%$.

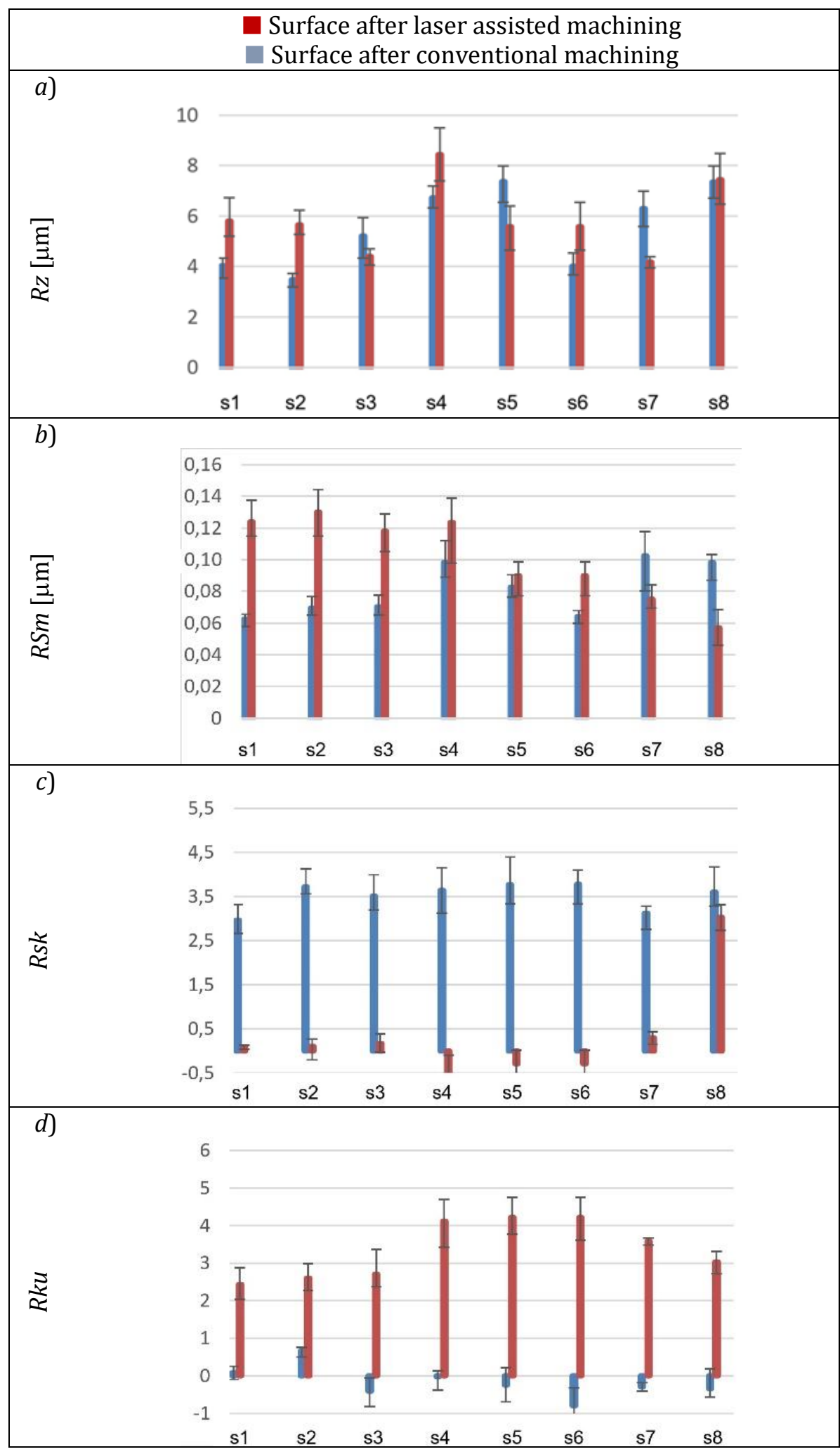

Fig. 3. Comparison of average values of $R z$ (a), $R S m$ (b), Rsk (c) and $R k u$ (d) parameters for surfaces after treatment with laser assistance and without laser assistance 
Very unfavorable results were obtained at a larger depth of cut (s5 and s7). In the seventh series, the parameter increased: $R a$ - by approximately $78 \%, R t$ - by approximately $54 \%, R z$ - by approximately $51 \%$. This may be due to greater plasticization of the workpiece. The cutting speed was lower, hence the material was removed more slowly than in the case of $s 2$, so that the heat impact on the surface lasted longer and the workpiece was more intensively softened.

In the case of turning without laser assistance, the mean distance between the $R S m$ roughness profile elevations is close to the feed value. Due to the use of LAM during cutting, plastic flow of the workpiece occurs, therefore the values are different from the feedrate per revolution.

As already noted, the use of LAM strongly affects the amplitude and skewness of the roughness profile (figs. 3c and 3d). When LAM is used, the distribution of $R s k$ values is clearly shifted to the right compared to conventional machining, characterized by a more centralized distribution, and Rku kurtosis is much closer to zero.

Laser assist does not have such significant impact on the mean square slope of the $R d q$ profile. In most tests, the differences are small (only in cases s5 and s7, there is greater plasticization of the material and more pronounced increase in $R d q$ value can be seen).

\section{Summary}

Considering the roughness of the surface, the most advantageous for machining X2CrNiMo17-12-2 stainless steel turned out to be the use of laser turning assistance and cutting parameters: $a_{\mathrm{p}}=0.3 \mathrm{~mm}, v_{\mathrm{c}}=75$ $\mathrm{m} / \mathrm{min}$ and $f=0.15 \mathrm{~mm} / \mathrm{rev}$.

Due to the risk of the material becoming too plasticized, it is disadvantageous to heat it longer, i.e. to use low cutting speeds or feedrates.

LAM technology allows to improve the quality of the surface made by reducing the value of roughness parameters by up to half.

\section{REFERENCES}

[1] Bleicher F., Finkeldei D., Siller A. "Machining of difficult-to-cut materials". Annals of DAAAM and Proceedings of the International DAAAM Symposium. 27, 1 (2016): 473-479.

[2] Grzesik W. „Wpływ topografii powierzchni na właściwości eksploatacyjne części maszyn”. Mechanik. 8-9 (2015): 587-593, http://dx.doi.org/10.17814/mechanik.2015.8-9.493.

[3] Przestacki D., Chwalczuk T., Wojciechowski S. "The study on minimum uncut chip thickness and cutting forces during laser-assisted turning of WC/NiCr clad layers". International Journal of Advanced Manufacturing Technology. 91 (2017): 3887-3898.

[4] Wojciechowski S., Przestacki D., Chwalczuk T. "The evaluation of surface integrity during machining of Inconel 718 with various laser assistance strategies". MATEC Web of Conferences. 136, (2017): 010061-01006-5.

[5] Felusiak A., Chwalczuk T., Wiciak M. "Surface roughness characterization of Inconel 718 after laser assisted turning". MATEC Web of Conferences. 237 (2018): 01004-1-01004-6.

[6] Rahman Rashid R.A., Sun S., Wanga G., Dargusch M.S. "An investigation of cutting forces and cutting temperatures during laser-assisted machining of the Ti-6Cr-5Mo-5V-4Al beta titanium alloy". International Journal of Machine Tools and Manufacture. 63 (2012): 58-69.

[7] Bermingham M.J., Kent D., Dargusch M.S. "A new understanding of the wear processes during laser assisted milling 17-4 precipitation hardened stainless steel". Wear. 328-329 (2015): 518-530.

[8] Przestacki D., Bartkowska A., Kukliński M., Kieruj P. "The effects of laser surface modification on microstructure of 1.4550 Stainless steel". MATEC Web of Conferences. 237 (2018): 02009-1-02009-5.

[9] Palanisamy D., Senthil P. "Machinability Study of Laser Surface Treated 15-5 PH Stainless Steel". Materials and Manufacturing Processes. 31, 13 (2016): 1755-1762.

[10] Raghavan S., Melkote S., Hashimoto F. "Laser tempering based turning process for efficient machining of hardened AISI 52100 steel". Journal of Manufacturing Processes. 15, 3 (2013): 318-328.

[11] Bucciarelli A., Kuila P.D., Melkote S.N., Fortunato A. "Micro-machinability of A-286 Steel with and without Laser Assist". Procedia CIRP. 46 (2016): 432-435. 